\title{
MATHEMATICAL MODELING OF MICROBIAL GROWTH IN VACUUM-PACKAGED AND REFRIGERATED FRESH COW MEAT
}

Odangowei I. Ogidi ${ }^{\prime}$, Pere-Ere S. Tobia ${ }^{2}$, Mike N. Ayebabogha ${ }^{3}$, Ayebatitari P. Sunny ${ }^{4}$

Address (es):

Dr. Odangowei I. Ogidi

${ }^{1}$ Department of Biochemistry, Federal Polytechnic, Ekowe, Bayelsa State.

${ }^{2}$ Department of Microbiology, Federal polytechnic, Ekowe, Bayelsa State.

${ }^{3}$ Department of Biological Sciences, Niger Delta University, Wilberforce Island, Bayelsa State .

${ }^{4}$ Department of Science Laboratory Technology, Federal Polytechnic Ekowe, Bayelsa state.

*Corresponding author: ogidiodangowei@gmail.com

Corresponding

https://doi.org/10.36547/be.303

\section{ABSTRACT}

Fresh meat is a highly perishable product due to its biological composition. This study examined the effect of different storage time ( $24,48,72$ hours), gaseous permeability of packaging film (Aluminum foil and Polyethylene) on the growth of microorganisms (Bacteria and fungi) isolated from the refrigerated cow meat at constant temperature of $0^{\circ} \mathrm{C}$. Microbial growth was modeled using Gompertz and Linear Regression Models. The bacteria count was observed to decrease as the storage time increases. While fungi count was observed to increase with increasing storage time. Aluminum foil packaged cow meat samples recorded lower microbial growth when compared to polyethylene packaged samples. In Gompertz model, the specific growth rate $(\mu)$ of the test organisms was observed to increase significantly upon a shift of storage time. The transition from 24 hours to 48 hours resulted in large changes in the growth profile with increased maximum population density (MPD) of the test organisms. However, lag phase of approximately two hours for bacteria and five hours for fungi was observed. An increase of storage time from 48 hours to 72 hours, an accelerated $\mu$, higher MPD with reduced lag phase duration (LPD) was observed. In the linear regression model, the coefficient of determination ( $\mathrm{R}^{2}$ ) values for aluminum foil packaged samples was 0.3 and polyethylene packaged samples was 0.1 . Therefore, it can be concluded that varying storage time at constant temperature; $\mu$ and MPD of the test organisms significantly increased with decreasing LPD of both studied vacuum packaging films of the refrigerated fresh cow meat.

Keywords: Cow meat, Mathematical Models, Microorganisms, Refrigeration, Packaging Films

\section{INTRODUCTION}

Meat is defined as the flesh of animals used as food. The term 'fresh meat' includes meat from recently processed animals as well as vacuum-packed meat or meat packed in controlled-atmospheric gases, which has not undergone any treatment other than chilling to ensure preservation. The diverse nutrient composition of meat makes it an ideal environment for the growth and propagation of meat spoilage micro-organisms and common food-borne pathogens. It is therefore essential that adequate preservation technologies are applied to maintain its safety and quality (Aymerich et al., 2008). The processes used in meat preservation are principally concerned with inhibiting microbial spoilage, although other methods of preservation are sought to minimise other deteriorative changes such as colour and oxidative changes.

A number of interrelated factors influence the shelf life and keeping quality of meat, specifically holding temperature, atmospheric oxygen $\left(\mathrm{O}_{2}\right)$, endogenous enzymes, moisture (dehydration), light and, most importantly, micro-organisms. All of these factors, either alone or in combination, can result in detrimental changes in the colour (Faustmann and Cassens, 1990), odour, texture and flavour of meat. Although deterioration of meat can occur in the absence of micro-organisms (e.g., proteolysis, lipolysis and oxidation), microbial growth is by far the most important factor in relation to the keeping quality of fresh meat (Lambert et al., 1991; Okereke et al., 2017).

The normal bacterial microflora of fresh meat is very heterogeneous. It is mainly composed of mesophilic and psychrophilic microorganisms such as Acinetobacter, Moraxella, Brochotrixtermosphacta, Lactobacillus, Bacillus, Pseudomonas, and Enterobacteriaceae family genera such as Escherichia coli and Klebsiella sp. (ICMSF, 1983). The growth of microorganisms occurs at the expense of its soluble components, mainly carbohydrates, amino acids and lactic acid (Ingram and Simonsen, 1980). There is a little amount of studies on the storage qualities of cow meat. However, the storage stability of this product can be deduced by consideration of the general behaviour of meat spoilage flora, the composition of the meat, and its microbiological condition at packing plants.

Vacuum packaging and refrigeration are being increasingly used as techniques to extend the useful life of perishable foods such as fresh meat cuts, using packaging films with low permeability to oxygen (Giannuzzi et al., 1997; Osmanagaoglu, 2002: Coll et al., 2008). Combining low temperature and different packages can almost completely prevent microbial growth from occurring. The application of the concept of barriers intended to prevent development of spoilage and toxin-producing microorganisms growing by mean of combined methods is gaining acceptance. These methods may not provide adequate preservation when applied individually, but when they act together they can increase significantly its effectiveness. The handling of meat and its associated contamination, joined to the fluctuations of both ambient and refrigerated temperature is common either in developing countries or in countries with advanced technologies.

The need to ensure microbiological safety and quality of foods has increased the use of predictive microbiology, which is a powerful tool for predicting microorganism's growth rate under ambient conditions, and thereby determining its effective life under different conditions of time, storage temperature, $\mathrm{pH}$, etc, during manufacture and distribution. One of the most frequently used mathematical models is that of Gompertz (Gibson et al., 1988; Giannuzzi et al., 1997), which describes the microorganism response under different combinations of factors (Andres et al., 2001). Gompertz model is a type of mathematical model for a time series, named after Benjamin Gompertz (1779-1865). It is a sigmoid function which describes growth as being slowest at the start and end of a given time period. The right-hand or future value asymptote of the function is approached much more gradually by the curve than the left-hand or lower valued asymptote. Gompertz function was originally designed to describe human mortality (which states that the human death rate is the sum of an age-dependent component which increases exponentially with age and an age-independent component), but since has been modified to be applied in biology, with regard to detailing populations. This model permits the estimation of parameters such as lag phase duration (LPD), specific growth rate $(\mu)$ and maximum population density (MPD) of microorganisms under such conditions (Coll et al., 2008).

Therefore, the objective of this study was to carry out the mathematic modeling of microbial growth in vacuum packaged and refrigerated Fresh cow meat.

\section{MATERIALS AND METHODS}

\section{Sample collection}

Cow meat samples were bought from Tombia market and were taken to the Microbiological Laboratory of the Niger Delta University, Wilberforce Island Bayelsa State for analysis. Once in the laboratory, meat samples were cut aseptically into subsamples of $5 \mathrm{~cm}$ diameter by $1.5 \mathrm{~cm}$ high with a sterile scalpel.

\section{Packaging and refrigerated storage of the cow meat samples}

The samples were packaged into two films with different values of oxygen permeability: (a) low density polyethylene (aerobic condition) of $50 \mu \mathrm{m}$ thick, water vapour permeability WVP $=12 \mathrm{~g} \mathrm{~m}^{-2} \mathrm{day}^{-1} \mathrm{~atm}^{-1}$ at $30^{\circ} \mathrm{C}$ and oxygen transmission rate OTR $=5000 \mathrm{~cm}^{3} \mathrm{~m}^{-2} \mathrm{~atm}^{-1} \mathrm{day}^{-1}$ at $23^{\circ} \mathrm{C}$, and (b) Aluminum foil which is made from an aluminum alloy, 0.00017 and 0.0059 inches thick. Storage 
experiments with packaged refrigerated cow meat were performed at temperature of $0^{\circ} \mathrm{C}$. During the storage period microbial counts were determined for 24,48 and 72 hours varying storage times.

\section{Microbiological analysis}

Media used:

Salmonella- Shigalla Agar (SSA), Eosin Methylene blue (EMB), Sabouraud dextrose agar (SDA), Mannitol salt agar (MSA), Peptone water

\section{Procedure}

The cow meat beef from the polyethylene and aluminum foil was removed from the refrigerator and allowed to get back to room temperature. $1 \mathrm{~g}$ of the beef was aseptically weighed into $10 \mathrm{ml}$ of buffered peptone water and was left for 30 minutes. Then ten (10) fold serial dilution was carried out and at the tube $10^{-4}$ (dilution factor). $1 \mathrm{ml}$ was plated out into petri dish and a molten agar cooled at $45^{\circ} \mathrm{C}$ was poured and mixed with the inoculum (aliquote) to evenly spread. Culture was incubated at $35-37^{\circ} \mathrm{C}$ in an inverted position in the incubator for 24 hours (for bacteria) and 72-168 hours (for fungi).

\section{Enumeration of bacteria and fungi}

The colony forming unit (CFU) was determined after culture incubation using the formula stated below:

$$
C F U=\frac{\text { Number of colony counted }}{m l \text { of inoculum }} \times \text { Dilution factor }
$$

\section{Mathematical modeling}

Mathematical models allow us to describe the effects of the main factors affecting microbial growth parameters. One of the most recommended models is the Gompertz modified equation (Zwietering et al., 1990).

Original Gompertz equation:

Where,

$$
y=a \exp [-\exp (b-c t)] \quad 1
$$

$\mathrm{a}, \mathrm{b}$ and $\mathrm{c}$ are Gompertz model parameters

$\mathrm{t}$ is time

The original Gompertz model was reparameterized for the parameters $\mathrm{a}, \mathrm{b}$, and $\mathrm{c}$ to obtain biologically meaningful parameters, such as the maximum specific growth rate, $\mu m$ the lag time $\lambda$, and the asymptotic value $\mathrm{A}$.

The modified Gompertz equation:

$$
y=A \exp \left(-\exp \left[\frac{\mu m e}{A}(\lambda-t)+1\right]\right)
$$

\section{2}

Where,

A is Asymptotic value

$\mu m$ is maximum specific growth rate

$e$ is Euler's number (2.7182)

$\lambda$ is Lag phase

$\mathrm{t}$ is time

From this equation, the following derived parameters were obtained: specific growth rate $\mu=\mathrm{b}$ c/e $\left[\log \left(\mathrm{CFU} / \mathrm{cm}^{2}\right)\right.$ hours ${ }^{-1}$, with $\mathrm{e}=2.7182$; lag phase duration $\mathrm{LPD}=0.5 / \mu$ [hours $]$, maximum population density MPD $=\mathrm{a}+\mathrm{c}[\log$ $(\mathrm{CFU} / \mathrm{cm})]$. Data fits obtained from Gompertz model were analyzed. When the microbial counts in food remain constant or decrease during storage, it is possible to use the linear regression model (Coll et al., 2008).

The regression coefficient equation is shown below:

$$
r^{2}=\frac{a \Sigma y+b \Sigma x y-n \bar{y}^{2}}{\Sigma y^{2}-n \bar{y}^{2}}
$$

Where;

$a$ is the intercept of the linear curve

$\mathrm{b}$ is the slope of the linear curve

$\mathrm{n}$ is the number of variables

$\mathrm{x}$ is independent variable

$\mathrm{y}$ is the dependent variable

\section{RESULTS AND DISCUSSION}

\section{Microbial growth}

Table 1 shows the microorganism morphology according to the different media used. E.coli recorded highest growth rate for both packaging films at all the different storage times $(24,48$ and 72 hours) while Fungi shows lower growth rate as shown in Tables 3 and 4.

Table 1 Microorganism Morphology

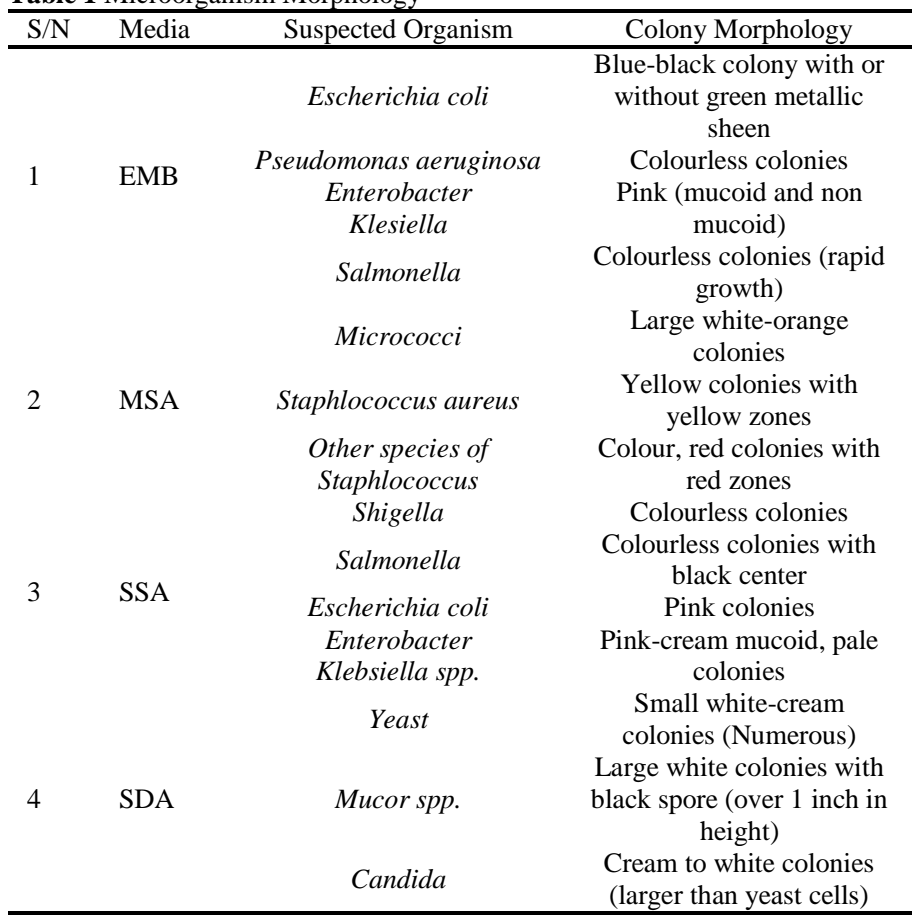

Legend: EMB-Eosin Methylene Blue; MSA-Mannitol Salt Agar; SSA-

\begin{tabular}{|c|c|c|c|}
\hline \multirow[t]{2}{*}{$\mathbf{S} / \mathbf{N}$} & \multirow[t]{2}{*}{ Test Organism } & \multicolumn{2}{|c|}{$\begin{array}{c}\text { Number of colonies at } 24 \text { hours in } \\
\text { CFU } / \mathrm{cm}^{2}\end{array}$} \\
\hline & & Aluminum foil & Polyethylene \\
\hline 1 & Escherichia coli & $2.9 \times 10^{6}$ & $3.1 \times 10^{6}$ \\
\hline 2 & $\begin{array}{l}\text { Staphlococcus } \\
\text { aureus }\end{array}$ & $2.78 \times 10^{6}$ & $2.9 \times 10^{6}$ \\
\hline 3 & Salmonella & $2.75 \times 10^{6}$ & $3.0 \times 10^{6}$ \\
\hline 4 & Shigella & $2.5 \times 10^{6}$ & $2.8 \times 10^{6}$ \\
\hline 5 & Fungi & $3 \times 10^{4}$ & $3.6 \times 10^{4}$ \\
\hline
\end{tabular}
Salmonella- Shigalla Agar; SDA-Sabouraud Dextrose Agar; S/N- Serial Number

Table 2 Number of colonies of microbial analysis of cow meat in $\mathrm{CFU} / \mathrm{cm}^{2}$ in 24 hours at $0^{\circ} \mathrm{C}$

Table 3 Number of colonies of microbial analysis of cow meat in $\mathrm{CFU} / \mathrm{cm}^{2}$ in 48 hours at $0^{\circ} \mathrm{C}$

\begin{tabular}{llcc}
\hline \multirow{2}{*}{ S/N } & Test Organism & \multicolumn{2}{c}{$\begin{array}{c}\text { Number of colonies at } \mathbf{4 8} \text { hours in } \\
\text { CFU/cm }\end{array}$} \\
\cline { 3 - 4 } 1 & & Aluminum foil & Polyethylene \\
2 & Staphlochia coli & $2.7 \times 10^{6}$ & $2.9 \times 10^{6}$ \\
2 & aureus & $2.6 \times 10^{6}$ & $2.8 \times 10^{6}$ \\
3 & Salmonella & $2.5 \times 10^{6}$ & $2.9 \times 10^{6}$ \\
4 & Shigella & $2.4 \times 10^{6}$ & $2.7 \times 10^{6}$ \\
5 & Fungi & $4.5 \times 10^{4}$ & $5 \times 10^{4}$ \\
\hline
\end{tabular}


Table 4 Number of colonies of microbial analysis of cow meat in $\mathrm{CFU} / \mathrm{cm}^{2}$ in 72 hours at $0^{\circ} \mathrm{C}$

\begin{tabular}{|c|c|c|c|}
\hline \multirow[t]{2}{*}{$\mathbf{S} / \mathbf{N}$} & \multirow[t]{2}{*}{ Test Organism } & \multicolumn{2}{|c|}{$\begin{array}{c}\text { Number of colonies at } 72 \text { hours in } \\
\text { CFU } / \mathrm{cm}^{2}\end{array}$} \\
\hline & & Aluminum foil & Polyethylene \\
\hline 1 & Escherichia coli & $2.65 \times 10^{6}$ & $2.8 \times 10^{6}$ \\
\hline 2 & $\begin{array}{l}\text { Staphlococcus } \\
\text { aureus }\end{array}$ & $2.5 \times 10^{6}$ & $2.7 \times 10^{6}$ \\
\hline 3 & Salmonella & $2.45 \times 10^{6}$ & $2.8 \times 10^{6}$ \\
\hline 4 & Shigella & $2.3 \times 10^{6}$ & $2.5 \times 10^{6}$ \\
\hline 5 & Fungi & $6 \times 10^{4}$ & $6.8 \times 10^{4}$ \\
\hline
\end{tabular}

Raw meat remains an important and probably the major source of human food borne infection with pathogenic bacteria. In spite of decades of effort it has been difficult to obtain food animals free of pathogenic bacteria. Vacuum-packaging and refrigeration are increasingly being used as two techniques for enhancing shelf-life of perishable foods such as cuts of fresh meat, using low-oxygen permeable packing materials (D'Agata et al., 2010). Here we demonstrate its usefulness in processing cow meat.

In this study a variety of microorganisms had been isolated from the refrigerated cow meat samples which are pathogenic in nature. Pathogenic bacteria contribute to other globally important diseases, such as Pneumonia, which can be caused by bacteria such as Streptococcus and Pseudomonas, and foodborne illnesses which can be caused by bacteria such as Shigella and Salmonella. Staphylococcus or Streptococcus are conditionally pathogenic and are also part of the normal human flora, they usually exist on the skin or in the nose without causing diseases. Pseudomonas aeruginosa are basically opportunistic pathogens, but they are inheritingly Multi drug resistant and also resistant to common antiseptics. These bacteria can cause disease mainly in people suffering from immunosuppresion. Escherichia coli count on the meat samples indicates the hygiene qualities of meat. The results obtained in this study showed the highest prevalent rate in the refrigerated meat samples at various times per hours (24, 48 and 72 hours) than other organisms in both the aluminum foil and polyethylene vacuum packages. This is in conformity with a study, who also reported high prevalence of $E$. coli (Zhao et al., 2001) and high prevalence of $E$. coli in retail meat market had also been reported (Kumar et al., 2001)
Staphylococci, which are natural flora of skin and mucous membranes of animals and human, can cause meat contamination (Nørrung et al., 2009). In the present study, $S$. aureus counts for the cow meat packaged with polyethylene at 24,48 and 72 hours were $2.9,2.8$ and $2.7 \times 10^{6} \mathrm{CFU} / \mathrm{cm}^{2}$ respectively. Aluminum foil at 24,48 and 72 hours were $2.78,2.6$ and $2.5 \times 10^{6} \mathrm{CFU} / \mathrm{cm}^{2}$ respectively (Table 2). These large numbers of $S$. aureus cells in the refrigerated meat samples indicate that sanitation, temperature control, or both, were inadequate. The results of the present study are in agreement with the previous findings (Haque et al., 2008; Tassew et al., 2010). Higher level of microbial contaminations including $S$. aureus of meat has also been reported previously (Voidarou et al., 2011).

The study also revealed the presence of Salmonella $s p$. and Shigella $s p$. The presence of these microorganisms can be attributed to contaminated waters used in abattoirs or the retailers. Salmonella has frequently been isolated from the abattoir environments and gastrointestinal tract of all farmed and wild animals (EFSA, 2007; Norrung et al., 2009). Prevalence of Salmonella sp and Shigella $s p$. in various raw meat samples of local market had also reported by another study which supports our study (Maharjan et al., 2006).

The fungi count of the study for both aluminum foil and polyethylene packaging films were observed to increase as the storage time increases (Tables 2-4). This might be because of their slow growth and relatively poor ability to compete with bacteria successfully, for they are most likely to be found in the foods in which the environment is less favorable for bacterial growth, e.g. low $\mathrm{pH}$, high salt or sugar content, low storage temperature, the presence of antibiotics, or exposure to irradiation. This findings was synonyms to the reports of Elrasheed, (2007).

\section{Mathematical modeling}

Tables 5-7 shows the mathematical modeling of the growth of microorganisms of cow meat at $0^{\circ} \mathrm{C}$ in 24,48 and 72 hours storage times. The derived parameters of Gompertz models such as $\mu$ and MPD increases as the storage time increases while LPD decreases at the increase of storage time. Figures 1 and 2 shows the linear regression results of both aluminum foil and polyethylene packaged cow meat samples with coefficient of determination $\left(\mathrm{R}^{2}\right)$ values of 0.3 and 0.1 respectively.

Table 5 Mathematical modeling of growth of microorganisms of cow meat beef at $0^{\circ} \mathrm{C}$ in 24 hours storage time

\begin{tabular}{llcccccc}
\hline \multirow{2}{*}{ Film } & Test Organism & \multicolumn{3}{c}{ Gompertz Parameters } & \multicolumn{3}{c}{ Derived Parameters } \\
\cline { 2 - 7 } & Escherichia coli & $\mathbf{A}$ & $\mathbf{B}$ & $\mathbf{c}$ & $\boldsymbol{\mu}$ & LPD & MPD \\
Aluminu & Staphlococcus aureus & 6.70 & 1.11 & 0.097 & 0.26 & 1.9 & 43.9 \\
m Foil & Salmonella & 6.75 & 1.11 & 0.096 & 0.25 & 2.0 & 44.2 \\
& Shigella & 6.85 & 1.11 & 0.097 & 0.25 & 2.0 & 44.1 \\
& Fungi & 11.3 & 1.06 & 0.095 & 0.24 & 2.1 & 44.4 \\
& Escherichia coli & 6.63 & 1.11 & 0.058 & 0.10 & 5.0 & 50.6 \\
Polyethy & Staphlococcus aureus & 6.70 & 1.11 & 0.098 & 0.26 & 1.92 & 43.7 \\
lene & Salmonella & 6.90 & 1.10 & 0.096 & 0.26 & 1.92 & 43.9 \\
& Shigella & 6.70 & 1.11 & 0.097 & 0.26 & 2.0 & 45.3 \\
& Fungi & 11.1 & 1.10 & 0.059 & 0.11 & 4.0 & 43.8 \\
\hline
\end{tabular}

Legend: LPD- Lag phase duration, MPD- maximum population density, $\mu-$ specific growth rate, a: $\log \left(\mathrm{CFU} \mathrm{cm}^{-2}\right), \mathrm{c}: \log$

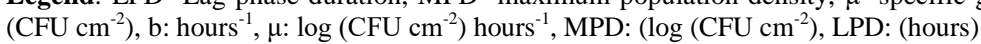

Table 6 Mathematical modeling of growth of microorganisms of cow meat beef at $0^{\circ} \mathrm{C}$ in 48 hours storage time

\begin{tabular}{llcccccc}
\multirow{2}{*}{ Film } & \multirow{2}{*}{ Test Organism } & \multicolumn{3}{c}{ Gompertz Parameters } & \multicolumn{3}{c}{ Derived parameters } \\
\cline { 3 - 7 } & Escherichia coli & $\mathbf{A}$ & $\mathbf{B}$ & $\mathbf{c}$ & $\boldsymbol{\mu}$ & $\mathbf{L P D}$ & MPD \\
Alumin & Staphlococcus aureus & 6.80 & 3.76 & 2.51 & 22.3 & 0.022 & 59.9 \\
um Foil & Salmonella & 6.85 & 3.75 & 2.50 & 22.1 & 0.023 & 59.7 \\
& Shigella & 6.74 & 2.49 & 21.9 & 0.023 & 59.7 \\
& Fungi & 10.87 & 3.73 & 2.48 & 21.7 & 0.023 & 59.8 \\
& Escherichia coli & 6.70 & 2.32 & 1.57 & 7.33 & 0.070 & 57.8 \\
Polyeth & Staphlococcus aureus & 6.73 & 2.32 & 2.55 & 14.0 & 0.035 & 59.8 \\
ylene & Salmonella & 6.70 & 2.32 & 2.54 & 13.9 & 0.036 & 59.7 \\
& Shigella & 6.77 & 2.31 & 2.52 & 14.1 & 0.038 & 59.8 \\
& Fungi & 10.76 & 1.82 & 1.58 & 4.9 & 0.036 & 59.7 \\
\hline
\end{tabular}

Legend: LPD- Lag phase duration, MPD- maximum population density, $\mu$ - specific growth rate, a: $\log \left(\mathrm{CFU} \mathrm{cm}^{-2}\right), \mathrm{c}: \log$ $\left(\mathrm{CFU} \mathrm{cm} \mathrm{cm}^{-2}\right)$, b: hours ${ }^{-1}, \mu: \log \left(\mathrm{CFU} \mathrm{\textrm {cm } ^ { - 2 }}\right)$ hours $^{-1}$, MPD: $\left(\log \left(\mathrm{CFU} \mathrm{cm} \mathrm{cm}^{-2}\right)\right.$, LPD: (hours) 
Ogidi et al., 2021 in Bacterial Empire

Table 7 Mathematical modeling of growth of microorganisms of cow meat beef at $0^{\circ} \mathrm{C}$ in 72 hours storage time

\begin{tabular}{llllllll}
\hline Film & Test Organism & \multicolumn{5}{l}{ Gompertz Parameters } & \multicolumn{4}{c}{ Derived parameters } \\
\cline { 3 - 7 } Alumin & Escherichia coli & A & B & c & $\mu$ & LPD & MPD \\
um Foil & Staphlococcus aureus & 6.85 & 3.05 & 6.02 & 43.36 & 0.012 & 82.24 \\
& Salmonella & 6.87 & 3.03 & 5.97 & 42.52 & 0.012 & 81.92 \\
& Shigella & 6.93 & 3.01 & 5.95 & 42.24 & 0.012 & 82.69 \\
& Fungi & 10.6 & 2.31 & 3.89 & 41.48 & 0.012 & 81.92 \\
Polyeth & Escherichia coli & 6.73 & 3.06 & 6.07 & 15.68 & 0.032 & 69.02 \\
ylene & Staphlococcus aureus & 6.77 & 3.05 & 6.04 & 43.1 & 0.011 & 82.56 \\
& Salmonella & 6.73 & 3.43 & 6.07 & 49.4 & 0.011 & 82.37 \\
& Shigella & 6.85 & 3.03 & 5.96 & 42.5 & 0.010 & 82.56 \\
& Fungi & 10.45 & 2.33 & 3.91 & 16.19 & 0.031 & 81.86 \\
\hline
\end{tabular}

Legend: LPD- Lag phase duration, MPD- maximum population density, $\mu$ - specific growth rate, a: $\log \left(\mathrm{CFU} \mathrm{cm}^{-2}\right), \mathrm{c}: \log$ $\left(\mathrm{CFU} \mathrm{cm} \mathrm{cm}^{-2}\right)$, b: hours ${ }^{-1}, \mu: \log \left(\mathrm{CFU} \mathrm{\textrm {cm } ^ { - 2 } ) \text { hours }}{ }^{-1}\right.$, MPD: $\left(\log \left(\mathrm{CFU} \mathrm{cm} \mathrm{cm}^{-2}\right)\right.$, LPD: (hours)

The quality and shelf life of foods are often determined by the growth of microorganisms. Mathematical models can be used to predict the change in quality of a food in time and can therefore be applied to estimate the shelf life of foods. The models can help to decrease the required amount of costly and time consuming challenge tests, may help to design more efficient ways of challenge testing, and finally can be used for distribution chain optimization. Another important feature of models is the acquisition of improved knowledge of the factors that determine food quality.

Tables 5-7 shows the Gompertz's parameters and its derivatives for the microbial growth of analyzed microorganisms from the surfaces of the meat samples packaged in both aluminum foil and polyethylene at temperature of $0^{\circ} \mathrm{C}$ with storage time of 24,48 and 72 hours. A good fit of the experimental results with respect to the model was observed. For both Bacteria and fungi counts, vacuum packaged in aluminum foil and polyethylene samples was modeled by the Gompertz modified equation, which fungi lag phase duration (LPD) values were higher than bacteria. While for maximum population density (MPD) values, fungi was observed to be higher for both aluminum foil and polyethylene in 24 hours and bacteria (E.coli and Salmonella sp.) were observed to be highest at 48 and 72 hours. These findings were in agreement with the works of Rivas et al., (2014). For samples packaged in polyethylene, the highest values of specific growth rate $(\mu)$ were observed in the case of Salmonella $s p$ in all the different storage times at $0^{\circ} \mathrm{C}$ temperature. While for samples packaged in aluminum foil, the highest value was observed in E. coli in 24,48 and 72 hours at $0^{\circ} \mathrm{C}$ constant temperature. The specific growth rate $(\mu)$ of the test organisms was observed to increase significantly upon a shift of storage time at temperature $0^{\circ} \mathrm{C}$. The transition from 24 hours to 48 hours resulted in large changes in the growth profile with increase in maximum population density (MPD) of microorganisms. However, lag phase of approximately two hours for bacteria and five hours for fungi was observed, after which the cell growth continues, albeit at a higher specific rate. An increase of storage time from 48 hours to 72 hours an accelerated specific growth rate, higher maximum population density with reduced lag phase duration was observed. These results were in accord with the findings of Pena $\boldsymbol{e t}$ al., (2013) and Maria-Leonor et al., (2015).

The test organism's results in cow meat packaged in aluminum foil and polyethylene were modeled by the linear regression model with coefficient of determination $\left(\mathrm{R}^{2}\right)$ values of 0.3 and 0.1 respectively, showing a weak positive linear relationship (Figures 1 and 2). The linear regression model results were in accordance with the works of Pena et al., (2013).

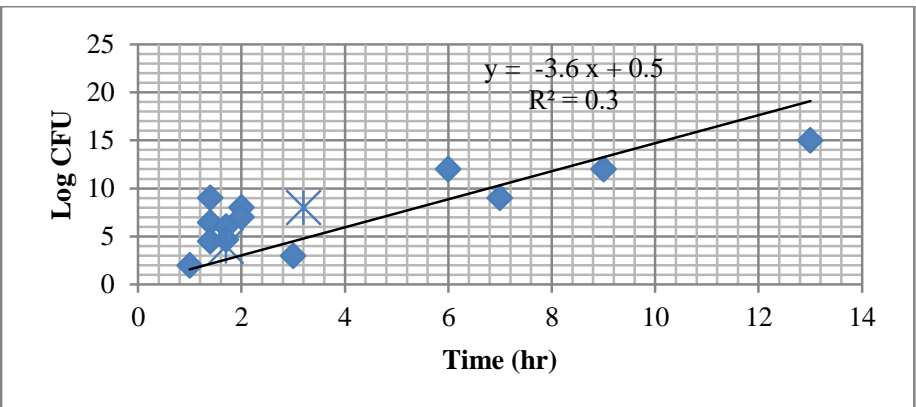

Figure 1 Linear Regression Model for Aluminum Foil Packaged cow meat samples

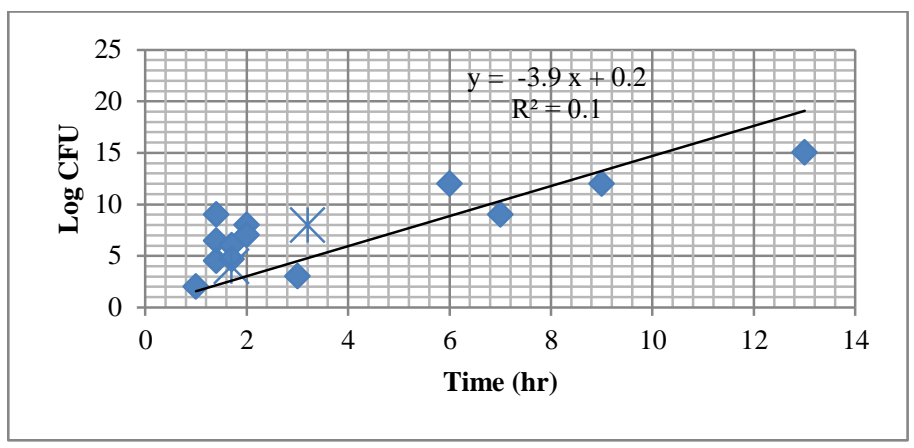

Figure 2 Linear Regression Model for Polyethylene Packaged cow meat samples

\section{CONCLUSION}

In the present study it can be concluded that refrigeration preservative method at constant temperature $0^{\circ} \mathrm{C}$, microorganism growth rate increases more on the vacuum packed polyethylene than aluminum foil which can be attributed to lower oxygen permeability rate of the aluminum foil packaging films. Also, bacteria count tends to decrease as the storage time increases while fungi count increases with increasing storage time, this might explains that fungi has a slower growth rate and relatively poor ability to compete with bacteria growth successfully, for they are most likely to be found in the foods in which the environment is less favorable for bacterial growth. Microbial growth was modeled using Gompertz and Linear Regression Models. The lowest microbial counts were obtained at 24 hours storage time. The specific growth rate $(\mu)$ of the test organisms was observed to increase significantly upon a shift of storage time at temperature of $0^{\circ} \mathrm{C}$. The transition from 24 hours to 48 hours resulted in large changes in the growth profile with increase in MPD of microorganisms. However, lag phase of approximately two hours for bacteria and five hours for fungi were observed, after which the cell growth continues, albeit at a higher specific rate. An increase of storage time from 48 hours to 72 hours an accelerated specific growth rate, higher maximum population density with reduced lag phase duration was observed. The test organism's results in cow meat packaged in aluminum foil and polyethylene were modeled by the linear regression model with coefficient of determination $\left(\mathrm{R}^{2}\right)$ values of 0.3 and 0.1 respectively, showing a weak positive linear relationship.

\section{REFERENCES}

Andrés, S., Giannuzzi, L. \& Zaritzky, N.E. (2001). Mathematical modeling of microbial growth in packaged refrigerated orange juice treated with chemical preservatives. J. Food Sci. 66, 724-728. https://doi.org/10.1111/j.13652621.2001.tb04628.x

Aymerich, T., Picouet, P. A., \& Monfort, J. M. (2008). Decontamination technologies for meat products. Meat Science, 78, 114-129. https://doi.org/10.1016/j.meatsci.2007.07.007

Coll Cárdenas, F., Giannuzzi, L.\& Zaritzky, N.E. (2007). Modelling microbial growth in meat broth with added lactic acid under refrigerated storage. Int. J.Food Sci. Technol. 42, 175-184. https://doi.org/10.1016/j.meatsci.2007.12.003 
Coll Cárdenas, F., Giannuzzi, L. \& Zaritzky, N.E. (2008). Predictive Equations to Assess the Lactic Acid and Temperature on Bacterial Growth in a Model Meat System. In: Gutiérrez Lopez, G.; Barbosa-Cánovas, G.; Welti-Chanes, J. y Parada Arias, E. (eds). Food Engineering: Integrated Approaches, Ch 24, p. 345358. https://doi.org/10.1007/978-0-387-75430-7

D’Agata, M., Nuvoloni, R., Pedonese, F., Russo, C., D’Ascenzi, C. \& Preziuso, G. (2010). Effect of Packaging and Storage Time on Beef Qualitative and Microbial Traits. J. Food Quality.33, 352-366. https://doi.org/10.1111/j.17454557.2010.00301.x

EFSA (2007). The community summary report on trends and sources of zoonoses, zoonotic agents and antimicrobial resistance and foodborne outbreaks in the European Union in 2006 The EFSA Journal. 130: 3-352. https://doi.org/10.2903/j.efsa.2007.130r

Elrasheed, A.A.M. (2007). The microbiological load of fresh and processed meat in Khartoum Tate-Sudan. University of Khartoum, Faculty of Veterinary Medicine. Published Ph.D thesis.

Faustmann, C., \& Cassens, R.G. (1990). The biochemical basis for discoloration in fresh meat: a review. In: Journal of Muscle Foods. 1, (3):217-243, 1990. https://doi.org/10.1111/j.1745-4573.1990tb00366.x

Giannuzzi, L., Pinotti, A. \& Zaritzky, N. (1997). Mathematical modelling of microbial growth in packaged refrigerated beef stored at deferent temperatures. Int. J. Food Microbiol. 39 (1-2),101-110. https://doi.org/10.1016/s01681605(97)00127-x

Gibson, A.M., Bratchell, N. \& Roberts, T.A. (1988). The efect of sodium chloride and temperature on rate and extent of growth of Clostridium botulinum type A in pasteurized pork slurry. J. Appl. Bacteriol. 62, 479-490. https://doi.org/10.1111/j.1365-2672.1987.tb02680.x

Haque M. A., M. P. Siddique, M. A. Habib, V. Sarkar \& K. A. Chou (2008). Evalvation of sanitry quality of goat meat obtained from slaughter yards and meat stalls at late market hours. Bangl. J. Vet. Med. 6 (1): 87-92. https://doi.org/10.3329/bjvm.v6i1.1343

Ingram, M. \& Simonsen, B. (1980). Meat and meat products. In: International Commission on Microbial Specifications for Foods (eds).Microbial Ecology of Foods. Vol. 2. Academic Press Inc., New York, U.S.A., 333-409. https://doi.org/10.1016/b978-0-12-363522-8.50009-2

International Commission on Microbiological Specifications for Foods. (1983). In: Microbial Ecology of Foods. Ch.15, Meat and meat products. Blackie Academic and Professional, London, United Kingdom.

Kumar, H.S., S. Ottu, I. Karunasagar \& I. Karunasagar (2001). Detection of Shiga-toxigenic Escherichia coli (STEC) in fresh seafood and meat marketed in Mangalore, India by PCR. Letters in Applied Microbiology, 33(5), 334-338. https://doi.org/10.1046/j.1472-765x.2001.01007.x

Lambert, A. D., Smith, J. P., \& Dodds, K. L. (1991). Shelf life extension and microbiological safety of fresh meat - a review. Food Microbiology, 8, 267-297. https://doi.org/10.1016/s0740-0020(05)80002-4

Maharjan, M., Joshi, V., Joshi, D.D. \& Manandhar, P. (2006). Prevalence of Salmonella Species in Various Raw Meat Samples of a Local Market in Kathmandu. Annals of the New York academy of sciences. Vol. 1081, 249-256. https://doi.org/10.1196/annals.1373.031

Maria-Leonor, P., Sandra, O., Maria-Dolores, E., Santiago, A. \& Alfredo, P. (2015). Comparison of primary models to predict microbial growth by the plate count and absorbance methods. Biomed Research International. 15(5): 1-14. http://dx.doi.org/10.1155/365025

Nørrung B., Andersen, J.K. \& Buncic, S. (2009). Main Concerns of Pathogenic Microorganisms in Meat Safety of Meat and Processed Meat. F. Toldrá, ed. (Springer New York), pp. 3-29. https://doi.org/10.1007/978-0-387-89026-5_1

Okereke, J.N., Ogidi, O.I. \& Anyalogbu, E.A. (2017). Kinetic Models Associated with Microbial and Bio-sorbent Treatment of Effluent - A Review. Foundation for African Development through International Biotechnology (FADIB) Proceedings Vol. 23, $12-22$.

Osmanagaoglu, O. (2002). Behaviour and biological control of bacteriocin producing Leuconostocs associated with spoilage of vacuum-packaged sucuk. Turk. J.Vet.Anim.Sci. 27, 471-480.

Pena, I., Coll, C.F., de la Sota, P., Villat, M.C., Noia, M.A., \& Mestorino, N. (2013). Mathematical modeling of microbial growth in refrigerated horsemeat. Its importance in the quality of meat. Revista Ciencias Veterinanas. 15(1): 65-76.

Rivas, E.M., de-Prado, E.G., Wrent, P., de-Siloniz, M.I., Barreiro, P., Correa, E.C., Conejero, F., Murciano, A. \& Peinado, J.M. (2014). A simple mathematical model that describes the growth of the area and the number of the area and the number of total and viable cells in yeast colonies. Letters in Applied Microbiology. 59, 594-603. http://dx.doi.org/10.1111/Iam.12314

Tassew H., Abdissa, A., Beyene, G. \& Gebre-Selassie, S. (2010). Microbial flora and food borne pathogens on minced meat and their susceptibility to antimicrobial agents. Ethiop J Health Sci. 20 (3): 137-143. https://doi.org/10.4314/ejhs.v20i3.69442

Voidarou, C., Vassos, D., Rozos, G., Alexopoulos, A., Plessas, S., Tsinas, A., Skoufou, M., Stavropoulou, E. \& Bezirtzoglou, E. (2011). Microbial challenges of poultry meat production. Anaerobe. 17 (6): 341-343. https://doi.org/10.1016/j.anaerobe.2011.05.018

Zhao, C., Ge, B.,Villena, J.D., Sudler, R. \& Yeh , E. (2001). Prevalence of Campylobacter spp., Escherichia coli and Salmonella serovars in retail chicken, Turkey, pork and beef from the Greater Washington D.C., Area. Applied and Environmental Microbiology, 67(12): 5431-5436. http://doi.org/10.1016/j.meatsci.2010.04.033

Zwietering, M.H., Jongenburger, I., Rombouts, F.M. \& Van'tRiet, K. (1990). Modelling of the bacterial growth curve. Appl. Environ.Microbiol. 56, 18751881. https://doi.org/10.1128/aem.56.6.1875-1881.1990 